\title{
Use of generated artificial road profiles in road roughness evaluation
}

\author{
Giuseppe Loprencipe $^{1} \cdot$ Pablo Zoccali $^{1}$
}

Received: 27 July 2016/Revised: 5 January 2017/ Accepted: 11 January 2017/Published online: 11 February 2017

(C) The Author(s) 2017. This article is published with open access at Springerlink.com

\begin{abstract}
In the evaluation of road roughness and its effects on vehicles response in terms of ride quality, loads induced on pavement, drivers' comfort, etc., it is very common to generate road profiles based on the equation provided by ISO 8608 standard, according to which it is possible to group road surface profiles into eight different classes. However, real profiles are significantly different from the artificial ones because of the non-stationary feature of the first ones and the not full capability of the ISO 8608 equation to correctly describe the frequency content of real road profiles. In this paper, the international roughness index, the frequency-weighted vertical acceleration $a_{\mathrm{w} z}$ according to ISO 2631, and the dynamic load index are applied both on artificial and real profiles, highlighting the different results obtained. The analysis carried out in this work has highlighted some limitation of the ISO 8608 approach in the description of performance and conditions of real pavement profiles. Furthermore, the different sensitivity of the various indices to the fitted power spectral density parameters is shown, which should be taken into account when performing analysis using artificial profiles.
\end{abstract}

Keywords Ride quality - International roughness index · Dynamic load index · Road surface irregularities · ISO $2631 \cdot$ ISO $8608 \cdot$ Real road profiles · Artificial road profiles

Giuseppe Loprencipe

giuseppe.loprencipe@uniroma1.it

1 Department of Civil, Building and Environmental Engineering, Sapienza University of Rome, Via Eudossiana 18, 00184 Rome, Italy

\section{Introduction}

Road pavement unevenness may induce detrimental effects such as the reduction in passengers' comfort and the increment of both dynamic loads on pavements and stress on vehicles' components.

The evaluation of the ride quality and the assessment of the effects on road vehicles due to the presence of irregularities on road pavements surface [1] are often performed using artificial profiles in order to have a full control over their geometric characteristics (e.g., roughness level, profile length) affecting the phenomenon. In addition, to validate the obtained results, a huge number of samples are necessary, which generally are not always available through in situ measurements because of they require considerable costs and time.

ISO 8608 [2] provides a method to classify road profiles according to a specific fitting process. Starting from the equation provided by ISO 8608 standard for the calculation of fitted power spectral density (PSD) of profile elevations, it is possible to generate random road profiles having different geometric characteristics, thus belonging to the desired road profile class.

Many studies are based on the use of these artificial road profiles in order to evaluate, for example, the dynamic load on road pavements due to roughness $[3,4]$ or to calculate the transfer function needed to estimate road roughness using vehicle acceleration measurements [5]. Moreover, many studies on the design and analysis of vehicle suspensions are often based on the use of artificial profiles $[6,7]$.

Real road profiles can be quite different from the artificial ones because in the first ones, generally, not all the harmonic components appear along the entire length of the pavement and, furthermore, the equation describing the 
artificial profiles, also used for the ISO 8608 classification, is a consequence of smoothing and fitting process. The main reason of the difference between them is probably that artificial profiles are stationary and homogenous signals and real profiles are often non-stationary and nonhomogenous signals. Artificial profiles do not contain various road distress along the profile. These distresses influenced the calculated road elevation PSD in the shortwave band.

Many authors, such as Kropáč and Múčka [8], have studied mutual relationships between various roughness evaluation methods, with a particular attention to the unevenness index $G_{\mathrm{d}}\left(n_{0}\right)$ and waviness $w$. These two parameters are defined in ISO 8608 standard, where the provided profiles classification is mainly based on the values of the first one.

In this paper, a set of real profiles belonging to the Italian road network and some generated artificial profiles are analyzed and compared, by calculating the international roughness index (IRI) and the dynamic load index (DLI) and evaluating the passengers' comfort as specified by ISO 2631 [9] through the whole-body vibration acceleration $\left(a_{\mathrm{wz}}\right)$. The three indices are used in combination because each of them is focused on a particular effect induced by the presence of irregularities along road pavement surface. Among them, IRI is the most common road roughness evaluation index actually used all over the world and it was developed in order to take into account several effects (e.g., comfort, dynamic load, maintenance). DLI, instead, is based on the assessment of the loads induced by trucks on road pavement due to the presence of irregularities. In addition, the ride quality assessment, that is, the main topic of the ISO 2631 standard, was evaluated by simulations, calculating the whole-body vibration perceived by road users inside a vehicle riding on a roughness pavement, as described by Cantisani and Loprencipe [10].

\section{Methodology and data}

ISO 8608 provides a method to describe and classify road profiles, based on their vertical displacement PSD.

The whole process required by ISO 8608 can be briefly summarized in the following three steps:

- calculating the fast Fourier transform (FFT) of the profile elevation signals, using also an appropriate window such as the Hanning one;

- representing the vertical displacement PSD in octave bands from the lowest calculated spatial frequency up to a center spatial frequency equal to $0.0312 \mathrm{cycles} / \mathrm{m}$, in the third octave bands from the last octave band up to a center frequency of 0.25 cycles $/ \mathrm{m}$ and in the twelfth octave bands up to the highest calculated spatial frequency (smoothing process);

- fitting the smoothed PSD by means of the general formula (1):

$G_{\mathrm{d}}(n)=G_{\mathrm{d}}\left(n_{0}\right) \cdot\left(\frac{n}{n_{0}}\right)^{-w}$,

where $G_{\mathrm{d}}$ is the displacement PSD in $\mathrm{m}^{3}, n$ is the spatial frequency, $n_{0}=0.1$ cycles $/ \mathrm{m}$ is the reference spatial frequency, $G_{\mathrm{d}}\left(n_{0}\right)$ is the PSD value at the reference spatial frequency $n_{0}$ (usually identified as $C$ ), and $w$ is the exponent of the fitted PSD (also known as waviness). An example of the output for the ISO 8608 process is depicted in Fig. 1, where displacement PSD versus spatial frequency is plotted in a bi-logarithmic plan.

Thus, using the fitted PSD, it is possible to describe the whole frequency content by means of two parameters: $G_{\mathrm{d}}\left(n_{0}\right)$ and $w$.

On the basis of the values of the $G_{\mathrm{d}}\left(n_{0}\right)$ parameter calculated, road profiles are cataloged as belonging to one of the classes (from A to $\mathrm{H}$ ) provided by ISO 8608 and depicted in Fig. 2.

Usually, paved road profiles hardly belong to classes worse than $\mathrm{D}$ because road agencies set intervention thresholds (using specific ride quality index such as IRI) above which optimal conditions are restored. For this reason, in Table 1 just the thresholds referred to the class A (very good), B (good), C (average) and D (poor) are reported.

In the next sections, a brief description of the main characteristics of the various kind of road profiles (artificial and real) examined in this work is provided.

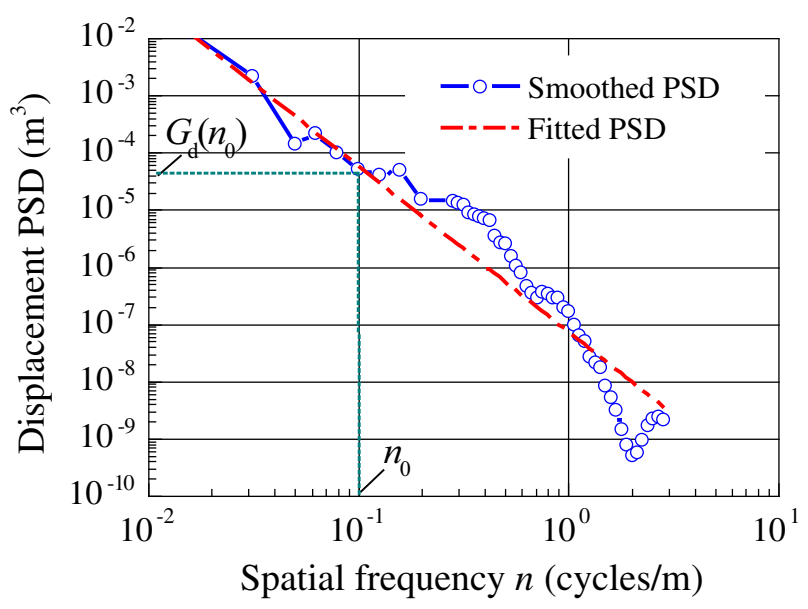

Fig. 1 Smoothed and fitted PSD according to ISO 8608 


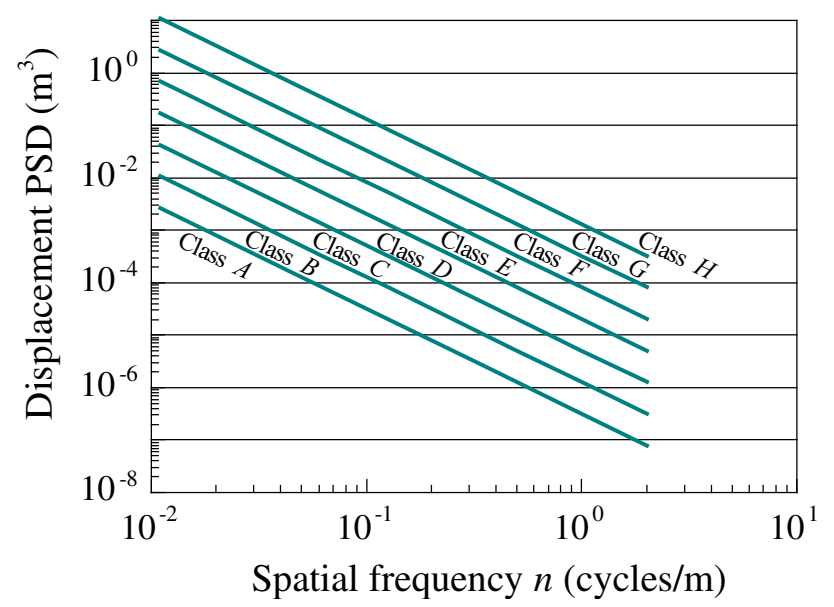

Fig. 2 Classification of road profiles according to ISO 8608 for a fit exponent $w=2$

Table 1 ISO 8608 thresholds of the first four classes (A-D)

\begin{tabular}{ll}
\hline ISO 8608 class & $G_{\mathrm{d}}\left(n_{0}\right)\left(10^{-6} \mathrm{~m}^{3}\right)$ \\
\hline A (very good) & $<32$ \\
B (good) & $32-128$ \\
C (average) & $128-512$ \\
D (poor) & $512-2,048$ \\
\hline
\end{tabular}

\subsection{Sample of real road profiles}

A set of about $200 \mathrm{~km}$ of real road profiles all belonging to minor roads was sampled with a spatial increment of $2.5 \mathrm{~cm}$. For each lane, two paths (right and left) at the main rutting alignments were measured using a high-speed laser/ inertial profilometer. Each profile path was divided in profile sections of $100 \mathrm{~m}$; thus, 1987 sections were taken into account.
Table 2 Percentage of real profiles belonging to a specific ISO 8608 class

\begin{tabular}{llll}
\hline Class A $(\%)$ & Class B (\%) & Class C (\%) & Class D (\%) \\
\hline 18.1 & 57.9 & 22.6 & 1.3 \\
\hline
\end{tabular}

To classify the road surface profiles according to ISO 8608 standard, the PSD of elevations was calculated using the FFT and the Hanning window. Then, the smoothing process described in the same ISO standard was performed. Finally, through the implementation of a MATLAB $\odot$ code, the fitted PSD was evaluated by means of Eq. (1), determining $G_{\mathrm{d}}\left(n_{0}\right)$ and $w$.

It was found that for the examined profiles, the normalized distribution of the $w$ parameter follows the trend shown in Fig. 3, with a mean value of 3.16 and a standard deviation of 0.17 .

As already reported in the previous section, paved road profiles generally belong to ISO 8608 classes from A to D. In fact, as shown in Table 2, the real road profiles analyzed in this study just belong to class A (very good), B (good), C (average) and $\mathrm{D}$ (poor), with a remarkable predominance of class B profiles.

\subsection{Sample of artificial profiles}

To generate artificial profiles to be used in simulations, it is necessary to assign two parameters that define the fitted PSD. The first one, $G_{\mathrm{d}}\left(n_{0}\right)$, identifies the class (from A to $\mathrm{H}$ ), while the second one, $w$, defines the slope. For the waviness, ISO 8608 suggests to assume a value equal to 2 .

As stated by Kropáč and Múčka [11], recent extensive road network measurements, performed in some countries such as Sweden [12], have shown that for most of the roads

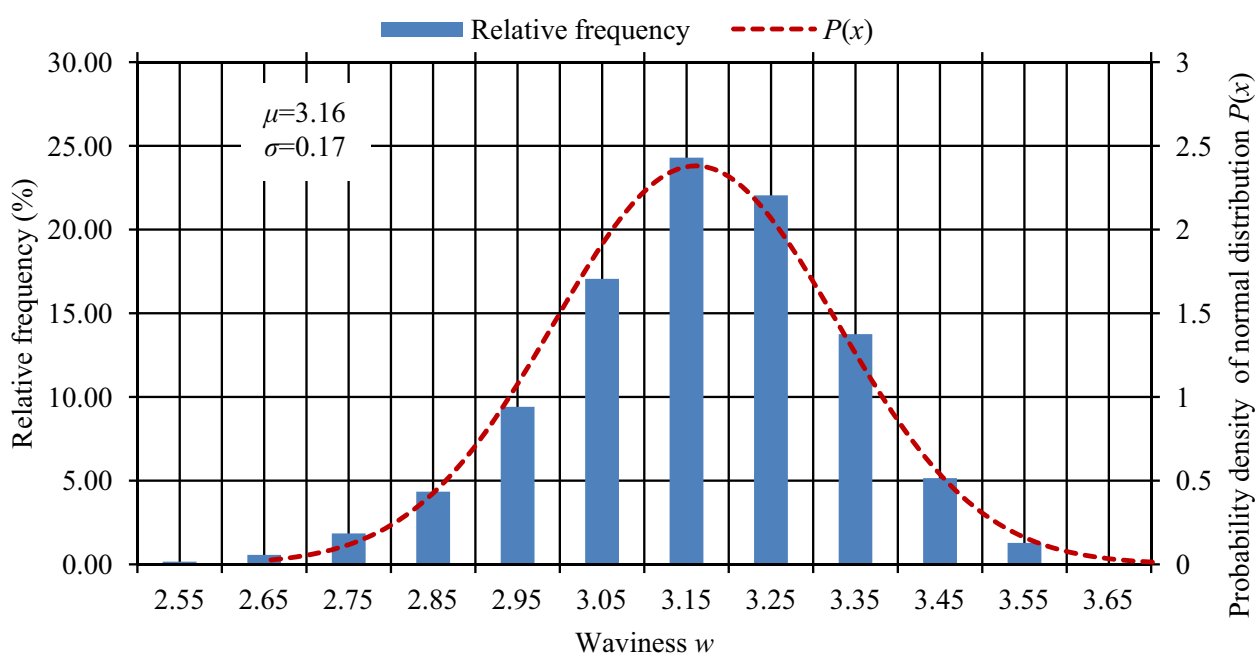

Fig. 3 Distribution of exponent $w$ calculated for all real roads sections 
waviness values vary between 1.5 and 3.5 with a mean value close to 2.5 .

It is considered appropriate to remember that, as already described by Múčka and Granlund [13], the two parameters defining the fitted PSD $\left[G_{\mathrm{d}}\left(n_{0}\right)\right.$ and $\left.w\right]$ are independent of each other and in particular, the second one provides information about the wavelength distribution in the spatial frequency range of interest. In fact, values greater than 2 mean that long waves are prevalent, while if lower, short ones are predominant.

In the generation of artificial profiles, the choice of waviness value requires particular attention because it may meaningfully affect the final results, and according to the kind of performed analysis, models could over- or underestimate the real behavior simulated.

To generate artificial profiles, the sinusoidal approximation described by Feng et al. [14] can be used. It is based on the hypothesis that a random profile of length $L$ can be approximated by a superposition of $N(\rightarrow \infty)$ sine waves, according to the Eqs. (2-4):

$z_{\mathrm{R}}(x)=\sum_{i=1}^{N} A_{i} \sin \left(\Omega_{i} x-\varphi_{i}\right)$

$A_{i}=\sqrt{\Phi\left(\Omega_{i}\right) \frac{\Delta \Omega}{\pi}}$

$\Delta \Omega=\frac{\Omega_{N}-\Omega_{i}}{N-1}$,

where $z_{\mathrm{R}}$ is the elevations profile in $\mathrm{m}, \Omega_{i}$ are the angular spatial frequencies in $\mathrm{rad} / \mathrm{m}, \varphi_{i}$ are the phase angles in $\mathrm{rad}$, the amplitudes $A_{i}$ are defined by (3), and $\Phi\left(\Omega_{i}\right)$ is the fitted PSD value at the angular spatial frequency $\Omega_{i}$.

The phase angles are considered as random variables, following a uniform distribution in the interval $[0,2 \pi)$.

Starting from the ISO 8608 fitted PSD parameters $\left[G_{\mathrm{d}}\left(n_{0}\right)\right.$ and $\left.w\right]$ obtained for each real profile, a correspondent artificial profile was generated by means of the process previously described. Thus, 1,987 $\times 2$ (left and right) artificial profiles were generated.

As shown in Fig. 4a, b, where two comparisons between generated and real profiles are depicted, the artificial profiles, from the ISO 8608 fitting parameters, are not able to perfectly replicate the trend of the correspondent real profile.

In fact, several elevation differences are present along the profiles, mostly at the edges of each profile.

\section{Performed analysis}

In order to highlight the different results obtained for artificial and real road profiles, IRI, DLI, and the $a_{\mathrm{wz}}$ were calculated, as described in the following sections.
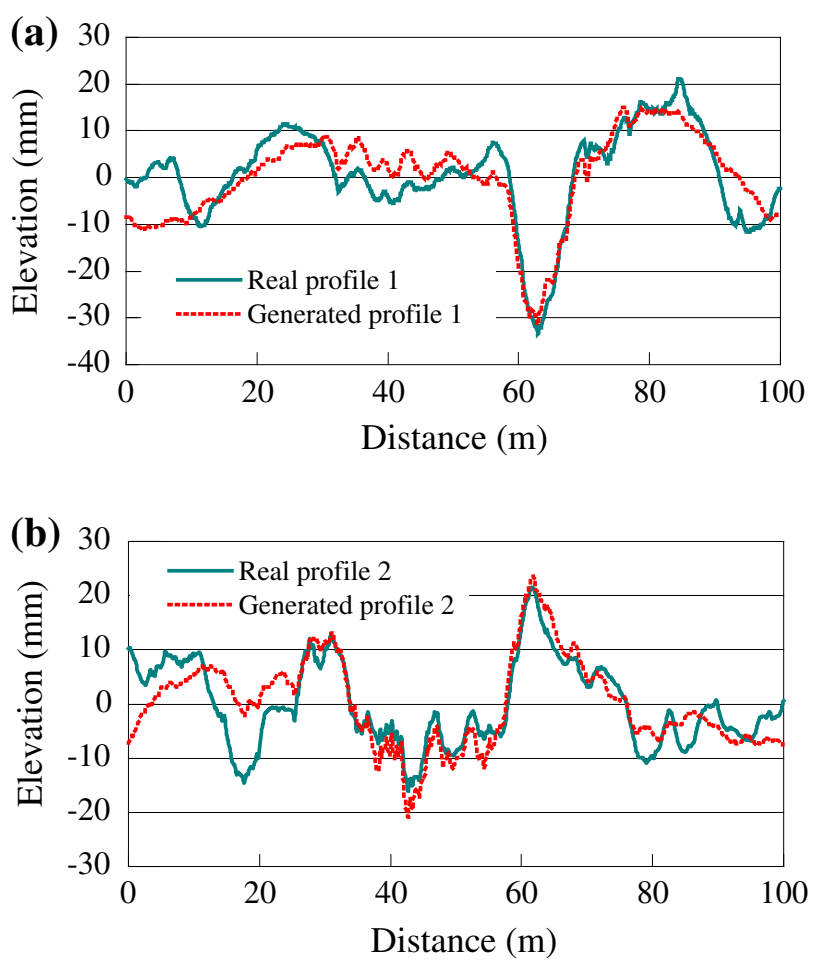

Fig. 4 Comparison between real measured profiles and artificial ones. a Profile 1. b Profile 2

\subsection{IRI}

The IRI has been elaborated from a World Bank study in the 1980s [15]. It is based on a mathematical model called quarter-car and developed in order to assess the ride quality on road pavements. The evaluation is performed by a model, calculating the simulated suspension motion on a profile and dividing the sum by the distance traveled according to the Eq. (5):

$V_{\mathrm{IRI}}=\frac{1}{l} \int_{0}^{l / v}\left|\dot{z}_{\mathrm{s}}-\dot{z}_{\mathrm{u}}\right| \mathrm{d} t$

where $l$ is the length of the profile in $\mathrm{km}, v$ is the simulated speed equal to $80 \mathrm{~km} / \mathrm{h}, \dot{z}_{\mathrm{s}}$ is the time derivative of vertical displacement of the sprung mass in $\mathrm{m}$, and $\dot{z}_{\mathrm{u}}$ is the time derivative of vertical displacement of the unsprung mass in $\mathrm{m}$. The final result $V_{\text {IRI }}$ is the IRI value and it is expressed in slope units (e.g., $\mathrm{m} / \mathrm{km}$ or $\mathrm{mm} / \mathrm{m}$ ).

In the present work, the IRI calculation was performed by means of a MATLAB $\odot$ code, where the algorithm proposed by ASTM E1926 [16] standard is implemented. The validation of the aforementioned code was carried out through a comparison of the obtained results with the ones provided by ProVAL3.60 [17], which is a software sponsored by FHWA in the USA and also incorporated in AASHTO smoothness specifications. 


\subsection{Whole-body vibration: ISO 2631}

To determine the frequency-weighted vertical acceleration on users due to road roughness [18], several simulations were performed using the 8 degree-of-freedom (DOF) fullcar models (Fig. 5) developed by Cantisani and Loprencipe [19] and calibrated in order to represent the behavior of a common passengers car [20].

Starting from the vertical accelerations in the time domain, calculated by this model, it is possible to determine the root mean square (RMS) accelerations through the evaluation of the PSD in correspondence of all the 23 one-third octave bands, representative of the frequency range of interest for the human response to vibrations (between 0.5 and $80 \mathrm{~Hz}$ ), as specified by ISO 2631 standard.

Once the RMS accelerations are known, it is possible to calculate the vertical weighted RMS acceleration $\left(a_{\mathrm{wz}}\right)$ using the Eq. (6):

$a_{\mathrm{w} z}=\sqrt{\sum_{i=1}^{23}\left(W_{k, i} \cdot a_{i z}\right)^{2}}$,

where $W_{k, i}$ are the frequency weightings in one-third octaves bands for seated position, provided by the standard, and $a_{i z}$ is the vertical RMS acceleration for the $i$ th one-third octave band. Then, the calculated values can be compared with the threshold values proposed by ISO 2631 for public transport (Table 3), in order to identify the comfort level perceived by users in all roads sections.

The current standard does not contain clearly defined vibration exposure limits between adjacent comfort levels because many factors (e.g., user age, acoustic noise and temperature) combine to determine the degree to which discomfort will possibly be noted or tolerated.

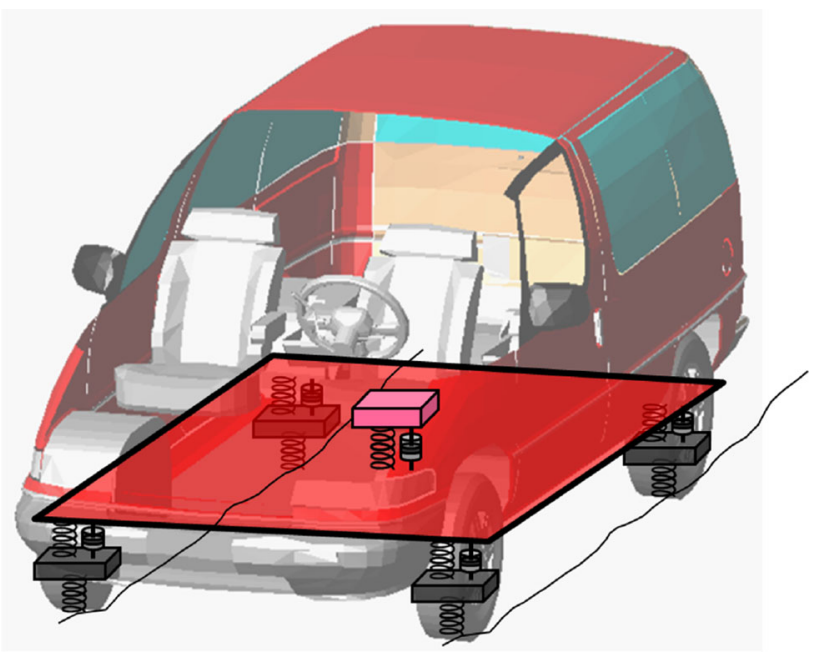

Fig. 5 Scheme of the full-car 8 DOFs
Table 3 Comfort levels related to $a_{\mathrm{w} z}$ threshold values as proposed by ISO 2631 for public transport

\begin{tabular}{ll}
\hline$a_{\mathrm{w} z}$ Values $\left(\mathrm{m} / \mathrm{s}^{2}\right)$ & Comfort level \\
\hline$<0.315$ & Not uncomfortable \\
$0.315-0.63$ & A little uncomfortable \\
$0.5-1$ & Fairly uncomfortable \\
$0.8-1.6$ & Uncomfortable \\
$1.25-2.5$ & Very uncomfortable \\
$>2$ & Extremely uncomfortable \\
\hline
\end{tabular}

For this reason, the ISO standard provides several comfort levels introducing an overlapping zone between two adjacent ones. In any case, the RMS value of the frequency-weighted vertical acceleration perceived inside vehicles may be compared with the values in Table 3, giving approximate indications of likely reactions to various magnitudes of overall vibration total values in public transport.

\subsection{DLI}

The DLI is a profile-based index developed in order to be representative of truck dynamic loads transmitted to road pavements due to the presence of irregularities on pavements surface [21].

DLI is calculated using the Eq. (7):

$V_{\mathrm{DLI}}=\sqrt{V_{1}+14 V_{2}}$,

where $V_{1}$ is the variance of elevations profile filtered in order to contain only wavelengths in the range of $6.7-17.9 \mathrm{~m}$ and $V_{2}$ is the variance of elevations profile containing just wavelengths from 1.8 to $3.3 \mathrm{~m}$. The choice of these wavelength ranges is based on considering a truck travelling at $96 \mathrm{~km} / \mathrm{h}$. Thus, the above-mentioned wavelength intervals correspond, respectively, to frequency ranges of $1.5-4 \mathrm{~Hz}$ and of $8-15 \mathrm{~Hz}$, in correspondence of which the main peaks on truck response function are found. The coefficient of 14 is a result from an optimization process for the relations between the dynamic load coefficient (DLC) and the 95th percentile dynamic load with DLI. The DLI is expressed in unit of $10^{-2}$ in. $(1$ in. $=25.4 \mathrm{~mm})$.

\section{Results and discussions}

A first analysis has been carried out in order to evaluate the capability of the ISO 8608 approach to be both adequate as road surface classification method and a useful tool for generating artificial profiles, concerned to compare the distribution of IRI, DLI and $a_{\mathrm{wz}}$ values calculated for real and artificial profiles. The artificial profiles considered in 


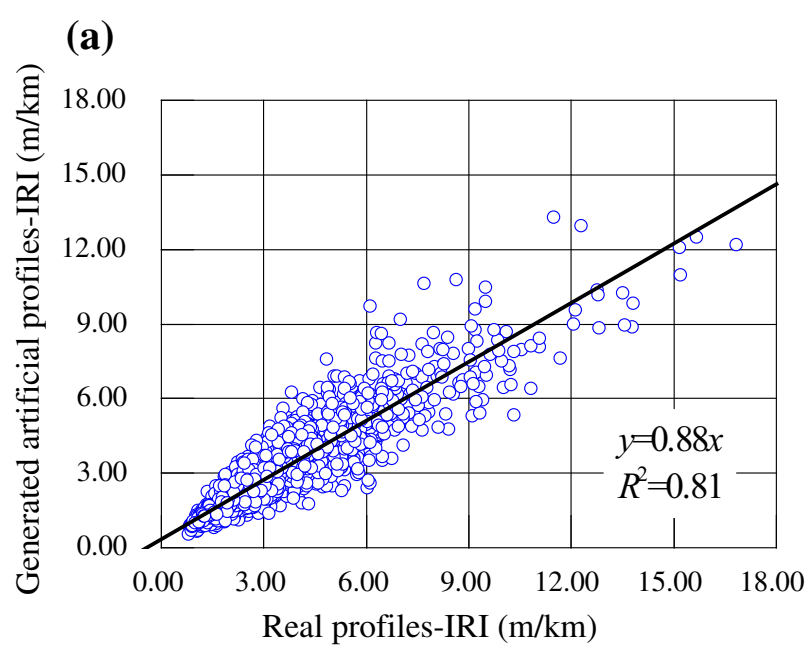

(b)
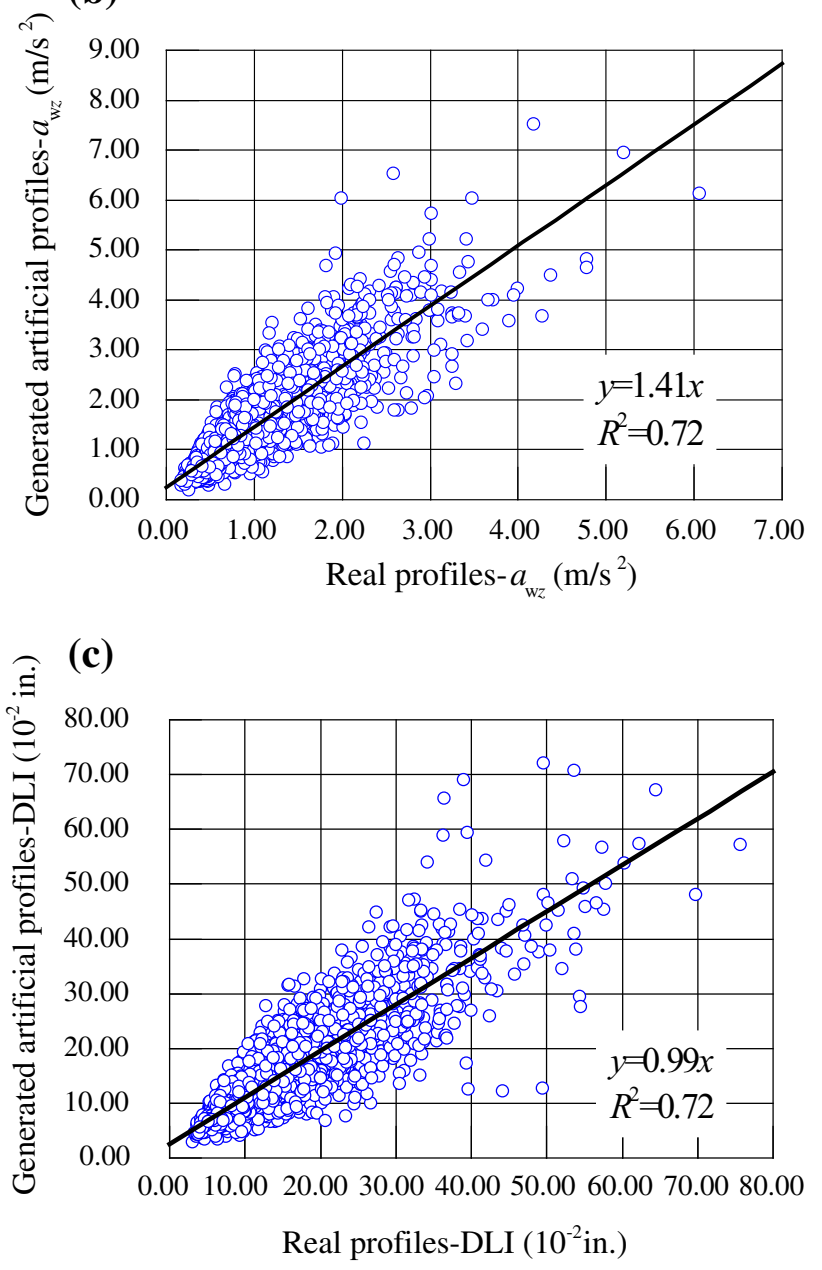

Fig. 6 Comparison of IRI (a), $a_{\mathrm{wz}}(\mathbf{b})$, and DLI (c) values between real and artificial profiles

this analysis were generated from the ISO 8608 fitting parameters $\left[G_{\mathrm{d}}\left(n_{0}\right)\right.$ and $\left.w\right]$ calculated for the real profiles sample.
Table 4 Basic statistical parameters of differences between IRI, $a_{\mathrm{wz}}$ and DLI

\begin{tabular}{lccc}
\hline Statistical parameter & $\Delta \mathrm{IRI}(\mathrm{m} / \mathrm{km})$ & $\Delta a_{\mathrm{wz}}\left(\mathrm{m} / \mathrm{s}^{2}\right)$ & $\Delta \mathrm{DLI}\left(10^{-2} \mathrm{in}.\right)$ \\
\hline Mean & -0.27 & 0.44 & 0.47 \\
$\mathrm{SD}$ & 0.68 & 0.40 & 4.10 \\
Minimum & -5.01 & -1.13 & -36.82 \\
Maximum & 3.55 & 4.04 & 30.00 \\
\hline
\end{tabular}

(a)
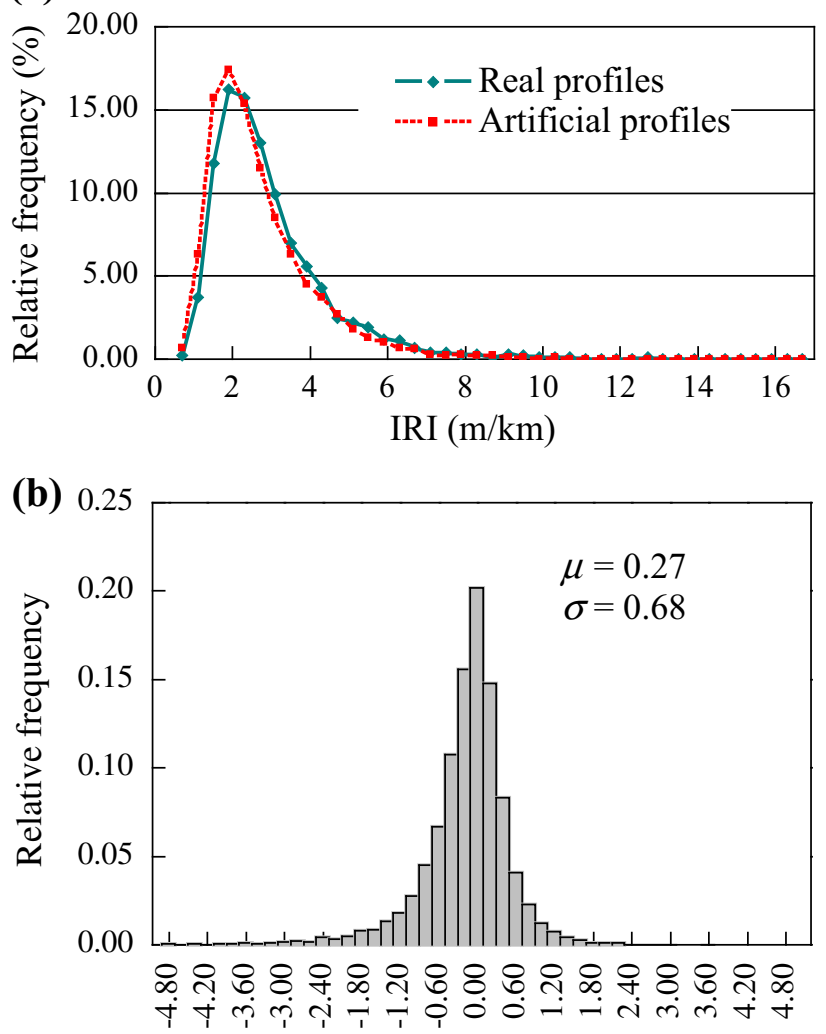

IRI difference value $(\mathrm{m} / \mathrm{km})$

Fig. 7 IRI values distributions for real and artificial profiles (a) and distribution of differences $\left(\mathrm{IRI}_{\text {artificial }}-\mathrm{IRI}_{\text {real }}\right)(\mathbf{b})$

The results obtained from the application of the three roughness evaluation methods provide a description of their different ability to catch the existing differences between real profiles and artificial ones. In fact, considering the whole amount of samples and comparing the values of indices calculated for each profile couple (real and artificial ones having the same ISO 8608 fitting parameters), the sensitivity of the three roughness evaluation approaches was found to be meaningfully different. In Fig. 6, scatter plots of the indices values calculated for both kinds of profiles are depicted. Applying a linear regression to the examined data, it was found that, in general, IRI 
(a)
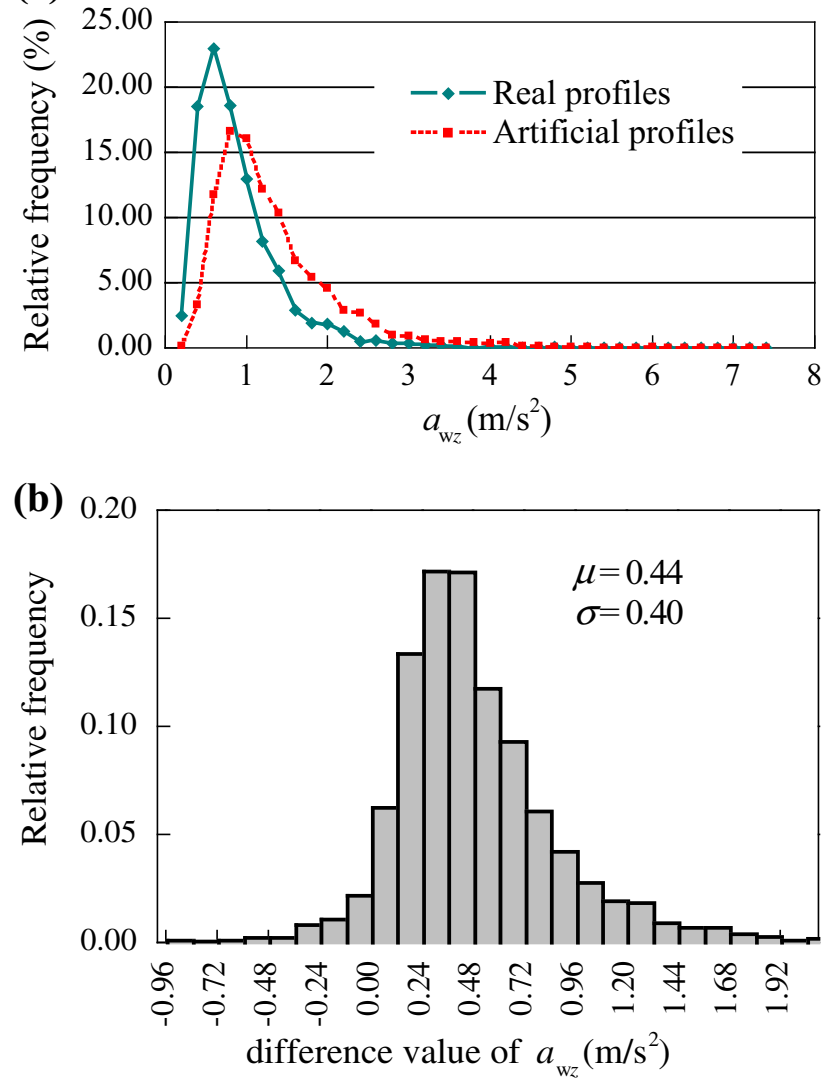

Fig. $8 a_{\mathrm{w} z}$ values distributions for real and artificial profiles (a) and distribution of differences $\left(a_{\mathrm{w} z \text {,artificial }}-a_{\mathrm{w} z \text {,real }}\right)$ (b)

values lower than the correspondent ones for real profiles were obtained considering artificial profiles (Fig. 6a), with a mean reduction of about $12 \%$. On the contrary, for the $a_{\mathrm{wz}}$ approach, a general increment equal to about $41 \%$ takes place (Fig. 6b), which confirms the major sensitivity of the ISO 2631 approach to the passage from real to artificial profiles. The DLI method, instead, seems to be less influenced by the differences between the two kinds of profiles, characterized by the same ISO 8608 fitting parameters. In fact, in this case, a slope very close to 1 was found, although the correspondent $R^{2}$ value was found to be lower than for IRI, as shown in Fig. 6c.

In addition, the basic statistical parameters (mean value, standard deviation, minimum and maximum values) of the differences between the indices values calculated for real and artificial profiles are reported in Table 4, where $\Delta \mathrm{IRI}=\mathrm{IRI}_{\text {artificial }}-\mathrm{IRI}_{\mathrm{real}}, \quad \Delta a_{\mathrm{wz}}=a_{\mathrm{w} z \text {,artificial }}-a_{\mathrm{w} z \text {,real }}$, and $\Delta \mathrm{DLI}=\mathrm{DLI}_{\text {artificial }}-\mathrm{DLI}_{\text {real }}$. From the statistical data, very close mean values were found for $a_{\mathrm{wz}}$ and DLI (respectively, 0.44 and 0.47), but different meanings should be assigned to them, considering the different ranges of values that characterize the two indices.
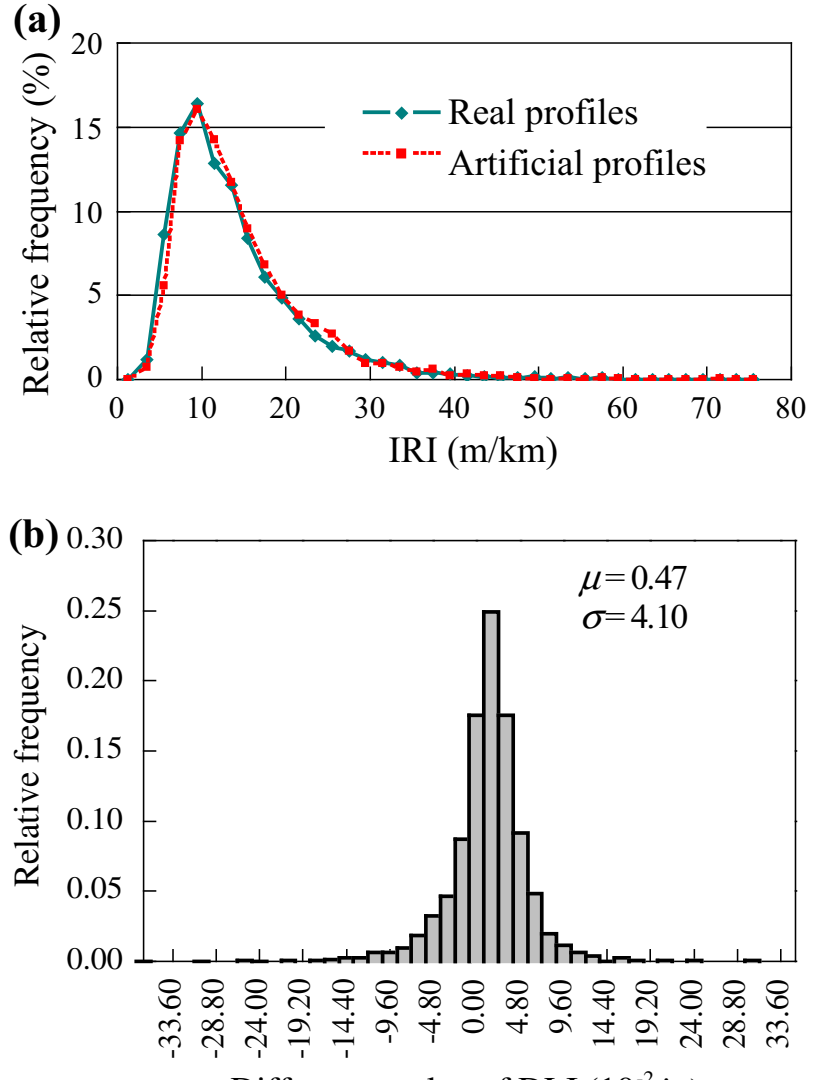

Difference value of DLI $\left(10^{-2}\right.$ in $)$

Fig. 9 DLI values distributions for real and artificial profiles (a) and distribution of differences $\left(\mathrm{DLI}_{\text {artificial }}-\mathrm{DLI}_{\text {real }}\right)(\mathbf{b})$

These results are confirmed by observing the distributions of IRI, $a_{\mathrm{w} z}$ and DLI values calculated for real and artificial profiles and depicted, respectively, in Figs. 7a, 8a and 9a. In fact, for IRI and DLI quite similar distributions were found, while for $a_{\mathrm{wz}}$ the distributions are very different, confirming the overestimation of users comfort when considering artificial profiles. Furthermore, in Figs. $7 \mathrm{~b}, 8 \mathrm{~b}$ and $9 \mathrm{~b}$ the distribution of the differences between indices values for artificial and real profiles is plotted.

The presented results show how the use of artificial profiles may lead to different results than the use of real ones, even if they have the same ISO 8608 classification parameters. In addition, the differences between the examined samples of real and artificial profiles are influenced by the type of roughness evaluation method used to assess them, as can be noted comparing the results obtained for the three different approaches considered in this paper (IRI, DLI and $a_{\mathrm{wz}}$ ).

The different results found from the above-mentioned analysis, are mainly caused due to the non-stationary feature of road surface profile signals. In fact, the results 

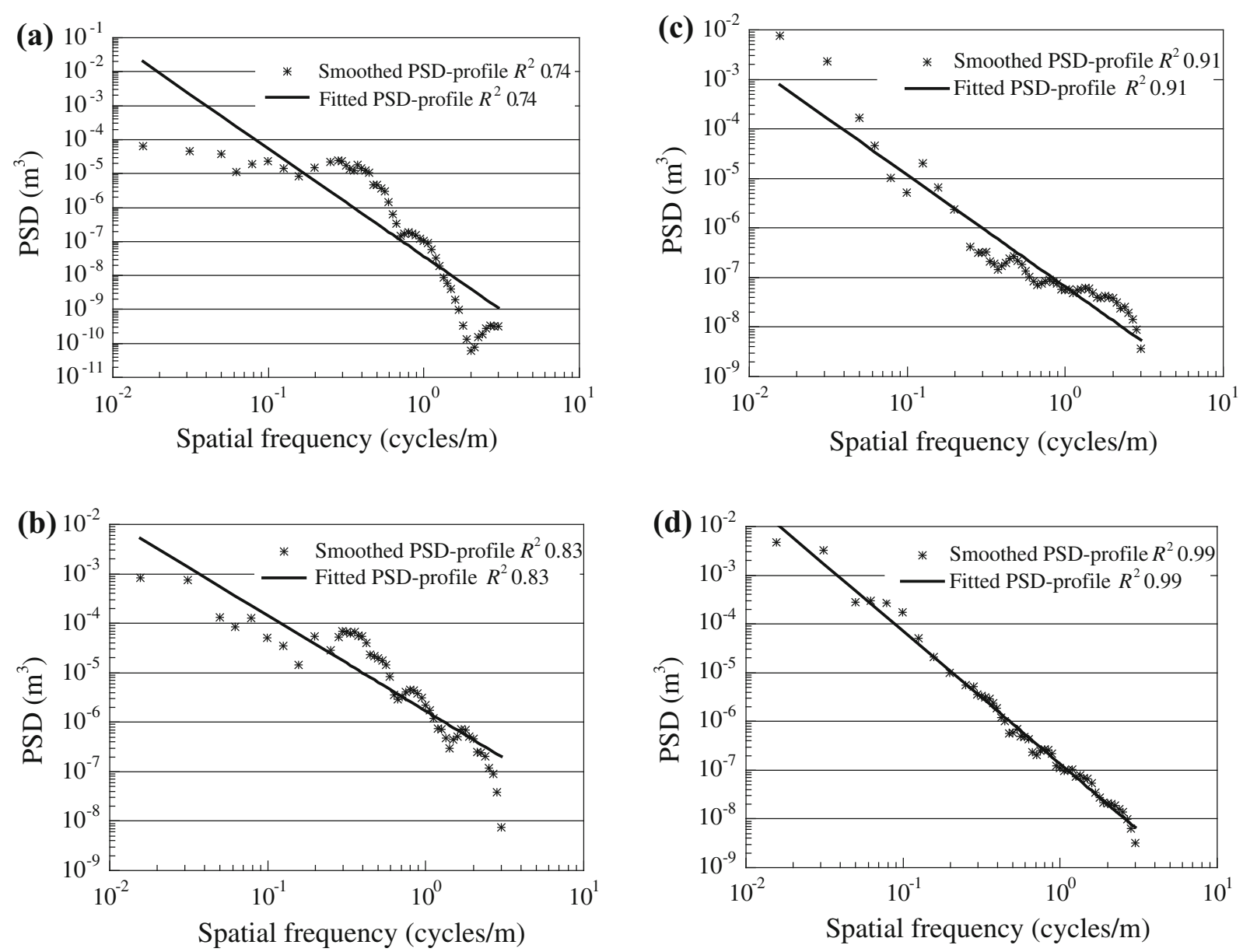

Fig. 10 Comparison between ISO 8608 fitted PSD and smoothed PSD for four real profiles sample having different $R^{2}$ values. a $R^{2}=0.74$. b $R^{2}=0.83$. c $R^{2}=0.91$. d $R^{2}=0.99$

obtained using various roughness evaluation criteria are affected in different way by the wavelength contents present along real profiles and, in particular, whether localized with continuity along the whole path length or just localized in certain areas [22].

Even if the non-stationary feature of real profiles is neglected, there is another aspect that may affect the analysis carried out using artificial profiles. In fact, the straight-line fit (in bi-logarithmic plan, see Fig. 1) described in ISO 8608 does not always provide a good representation of the PSD of real road profiles and, for this reason, other fitting approximation, such as two- and threewave bands, has been proposed in the literature [23].

As shown in Fig. 10, where the comparison between smoothed and fitted PSD for four different real profiles is depicted, using the ISO 8608 straight-line fit, the effects of some spatial frequency components may be under- or overestimated. The four examples have different $R^{2}$ values related to the fitting process (which are always quite high because calculated on the logarithmic values of the PSD),
Table 5 Main parameters of the $R^{2}$ distribution found for the real profiles sample

\begin{tabular}{ll}
\hline$R^{2}$ statistical parameters & \\
\hline Mean & 0.94 \\
SD & 0.03 \\
Minimum & 0.73 \\
Maximum & 0.99
\end{tabular}

and in particular, they are meant to be representative of the minimum (Fig. 10a), maximum (Fig. 10d) and of two intermediate values (Fig. 10b, c) of the $R^{2}$ range characterizing the whole real profiles set.

For the whole sample of real profiles examined in the present work, the distribution of the $R^{2}$ values presents the characteristic statistical parameters reported in Table 5.

The performed analysis has highlighted the limited ability of the ISO 8608 classification in fully describing real profiles, due to the high variability in their frequency 
content. However, considering the high number of parameters affecting the road pavements roughness and its evaluation, the usefulness of generated artificial profiles can be found in the analysis of specific parameters and in the assessment of their effects on ride quality, keeping in mind, however, that in that case ideal conditions are taken into account.

\section{Conclusion}

In this paper, a comparison between real and artificial profiles based on ISO 8608 approach has been carried out, using three different roughness evaluation methods: IRI, DLI and $a_{\mathrm{wz}}$. The final purpose was to evaluate the capability of the ISO 8608 classification to be representative of real profiles condition and performance, also assessing the significance of analysis performed using artificial profiles, generated from the ISO 8608 fitted PSD equation.

The main results can be summarized as follows:

- Artificial profiles, which differ from real ones due to their stationary feature, can be usefully used to perform sensitivity analysis of specific parameters influencing the vehicle pavement system. In this case ideal conditions are considered; therefore, it is necessary to pay attention to extending the obtained results to the case of real profiles, which present specific characteristics that should be taken into account.

- The analysis performed using artificial profiles, if extended to real cases, may induce an over- or underestimation of the results not evaluable a priori, also because strongly influenced by the type of profile evaluation method used. For this reason, a sensitivity analysis for the selected index should be carried out, for a better and a more correct interpretation of the results.

- The road profiles PSD fitting process suggested in the ISO 8608 standard, presents some limitation in describing the characteristics of real profiles; thus, other fitting approximation should be preferred to be used.

In conclusion, artificial profiles are a useful tool to be used as first approach to the vehicle pavement interaction analysis, with particular attention to suspension design; but, to correctly assess road pavement roughness and mainly the effects on users (e.g., ride quality), it is necessary to perform adequate in situ measurements, in order to evaluate the peculiar characteristic of the pavement that is meant to be analyzed.

Open Access This article is distributed under the terms of the Creative Commons Attribution 4.0 International License (http:// creativecommons.org/licenses/by/4.0/), which permits unrestricted use, distribution, and reproduction in any medium, provided you give appropriate credit to the original author(s) and the source, provide a link to the Creative Commons license, and indicate if changes were made.

\section{References}

1. Loprencipe G, Cantisani G, Di Mascio P (2015) Global assessment method of road distresses. In: Proceedings of the 4th international symposium on life-cycle civil engineering, IALCCE 2014, CRC Press, Balkema, pp 1113-1120

2. International Organization for Standardization-Mechanical vibration-road surface profiles-reporting of measured data. ISO 8608:1995, ISO/TC108/SC2, Geneve

3. Agostinacchio M, Ciampa D, Olita S (2013) The vibrations induced by surface irregularities in road pavements-a Matlab approach. European Transport Research Review. Springer, Berlin

4. McGetrick PJ, Kim CW, González A, O’Brien EJ (2013) Dynamic axle force and road profile identification using a moving vehicle. Int J Archit Eng Constr 2(1):1-16

5. González A, O'Brien EJ, Li YY, Cashell K (2008) The use of vehicle acceleration measurements to estimate road roughness. Veh Syst Dyn 46(6):483-499

6. Pazooki A, Rakheja S, Cao D (2012) Modeling and validation of off-road vehicle ride dynamics. Mech Syst Signal Process 28:679-695

7. Uys PE, Els PS, Thoresson M (2007) Suspension settings for optimal ride comfort of off-road vehicles travelling on roads with different roughness and speeds. J Terrramech 44(2):163-175

8. Kropáč O, Múčka P (2007) Indicators of longitudinal road unevenness and their mutual relationship. Road Mater Pavement Des 8(3):523-549

9. International Organization for Standardization-mechanical vibration and shock-evaluation of human exposure to whole-body vibration-part 1: general requirements. ISO 2631-1:1997, ISO/ TC108/SC4, Geneve, Switzerland: Multiple. Distributed through American National Standards Institute (ANSI)

10. Cantisani G, Loprencipe G (2010) Road roughness and whole body vibration: evaluation tools and comfort limits. J Transp Eng 136(9):818-826

11. Kropáč O, Múčka P (2009) Effects of longitudinal road waviness on vehicle vibration response. Veh Syst Dyn 47(2):135-153

12. Andrén P (2006) Power spectral density approximations of longitudinal road profiles. Int J Veh Des 40(1/2/3):2-14

13. Múčka P, Granlund J (2012) Is the road quality still better? J Transp Eng 138(12):1520-1529

14. Feng T, Yu-Fen H, Shun-Hsu T, Wes SJ (2006) Generation of random road profiles. CSME: B04-001: 1373-1377

15. Sayers MW (1995) On the calculation of international roughness index from longitudinal road profile. Transportation Research Record 1501, TRB, National Research Council, Washington, pp $1-12$

16. ASTM (2008) Standard practice for computing international roughness index of roads from longitudinal profile measurements. ASTM E1926, West Conshohocken, PA

17. ProVAL version 3.60 User's Guide (2016) The transtec group, Austin Texas. Available via http://www.roadprofile.com

18. Loprencipe G, Cantisani G (2013) Unified analysis of road pavement profiles for evaluation of surface characteristics. Mod Appl Sci 7(8):1

19. Cantisani G, Loprencipe G (2005) Irregolarità stradali in campo urbano: procedure per la valutazione del comfort di marcia. Strade e autostrade, EDI-CEM srl, Milano, IX-N (in Italian) 
20. Bonin G, Cantisani G, Loprencipe G, Sbrolli M (2007) Ride quality evaluation: 8 d.o.f. vehicle model calibration. III S.I.I.V. International Congress, Grafill S.r.l., Palermo

21. Chatti K, Lee D (2002) Development of new profile-based truck dynamic load index. Transp Res Rec J Transp Res Board 1806:149-159
22. Cantisani G, Fascinelli G, Loprencipe G (2012) Urban road noise: the contribution of pavement discontinuities. In: ICSDEC 2012: developing the Frontier of sustainable design, engineering, and construction, November 2012. ASCE, pp 327-334

23. Múčka P (2012) Longitudinal road profile spectrum approximation by split straight lines. J Transp Eng ASCE 138(2):243-251 